\title{
PRODUÇ̃̃O TEXTUAL NA DISCIPLINA DE LÍNGUA PORTUGUESA: CONCEPÇÃO DE PROFESSORES DE TERCEIRO E QUARTO CICLOS DO ENSINO FUNDAMENTAL
}

\author{
TEXTUAL PRODUCTION IN THE PORTUGUESE DISCIPLINE: CONCEPTION OF \\ TEACHERS OF THIRD AND FOURTH CYCLES OF BASIC EDUCATION
}

Eloara Tomazoni

Mestranda do Programa de Pós Graduação em Linguística - UFSC - Capes/Reuni

\begin{abstract}
Resumo
O tema desta proposta de estudo é descrever concepções docentes sobre o ensino e a aprendizagem da produção textual escrita na disciplina de Língua Portuguesa no terceiro e no quarto ciclos da Educação Básica em escolas estaduais de uma rede pública de ensino em município situado na região metropolitana de Florianópolis, no Sul do Brasil. O objetivo deste estudo é, à luz das teorizações que tratam do tema no campo da Linguística Aplicada, tanto quanto à luz do conteúdo de documentos educacionais oficiais em nível federal e estadual, descrever as concepções no que se refere a domínios ontológicos, teórico-epistemológicos e metodológicos. A pesquisa foi operacionalizada por meio de questionários entregues a seis professores de Língua Portuguesa de quatro escolas da Rede Estadual de ensino do município situado na região metropolitana de Florianópolis, no Sul do Brasil, e de entrevistas realizadas com dois desses professores. Os resultados apontam que os docentes têm certo conhecimento sobre as teorias, mas essas ainda não estão incorporadas na prática escolar. Tais resultados remetem a evidências significativas da histórica dissociação da ação escolar e dos estudos da esfera acadêmica, que parecem ainda não incidir na ação pedagógica.
\end{abstract}

Palavras-chave: Concepções de professores. Produção textual escrita. Gêneros discursivos/textuais.

\begin{abstract}
The subject of this study is to describe teachers conceptions about the teach and learn of the written text production in the discipline of Portuguese in the third and fourth cycles of basic education in state schools of a city situated in the metropolitan region of Florianópolis, in the South Brazil. The objective is, in the light of theories of that topic in the field of Applied Linguistic, and of the contents of official educational documents in federal and state level, to describe the conceptions in what it refers to ontological, theoricalepistemological and methodological domains. The research was operationalized by questionnaires given to the six teachers of Portuguese of the four schools of that city, and interviews realized with two of the teachers. The results indicate that the teachers have certain knowledge of the theories, but they are not incorporated in the school practice yet. Those results refer to significant evidences of the historical dissociation of the school
\end{abstract}


practice and the studies of the academic sphere that seems not to reflect on the pedagogic action.

Keywords: Conception of teachers. Written textual production. Discursive/textual genres.

\section{INTRODUÇÃO}

O tema desta proposta de estudo é descrever concepções docentes sobre o ensino e a aprendizagem da produção textual escrita na disciplina de Língua Portuguesa no terceiro e no quarto ciclos da Educação Básica em escolas estaduais de uma rede pública de ensino em município situado na região metropolitana de Florianópolis no Sul do Brasil.

Propomo-nos, à luz das teorizações que tratam do tema no campo da Linguística Aplicada, e do conteúdo de documentos educacionais oficiais em nível federal e estadual, descrever concepções que ancoram/norteiam o trabalho dos professores no que se refere ao ensino e aprendizagem da produção textual escrita. O objetivo é descrever concepções no que se refere a domínios ontológicos, entendidos como a visão das propriedades gerais, da essência da atividade de produção textual escrita - O que é a produção textual escrita nesses ciclos escolares?; domínios teórico-epistemológicos, entendidos como os princípios sobre os quais a atividade de produção textual escrita está fundamentada na escola - Quais são as bases teóricas que subsidiam a atividade desses docentes no ensino da produção textual escrita nesses ciclos?; e domínios metodológicos, entendidos como as bases procedimentais utilizadas nas atividades de produção textual escrita - Como se dá o encaminhamento metodológico dos processos de ensino e aprendizagem dessa mesma produção textual escrita? A pesquisa foi operacionalizada por meio de questionários entregues a seis professores de Língua Portuguesa das quatro escolas da Rede Estadual de ensino situadas em um município da região metropolitana de Florianópolis, no Sul do Brasil, e de entrevistas realizadas com dois desses professores.

Dentre as 26 perguntas que compuseram o questionário e que foram respondidas pelos docentes, abordaremos, aqui, apenas algumas delas - dadas as restrições do gênero artigo respectivas a concepções dos professores situadas nos domínios anteriormente mencionados. Na primeira seção de conteúdo, tematizamos concepções docentes tomadas sob o ponto de vista ontológico, a resposta à questão aberta cujo enunciado era: "Para você, o que é produção textual escrita? Justifique sua resposta". Por ser uma questão aberta, os participantes responderam-na livremente. Para uma melhor sistematização do trabalho e consideração do conteúdo das respostas, dividimos as concepções enunciadas em duas categorias: a) produção textual escrita concebida em uma perspectiva formalista; b) produção textual escrita concebida à luz do ideário do senso comum. Essa categorização prescinde de foco na dimensão sociointeracional do processo de produção textual abordagem cara aos documentos oficiais e ao estado da arte das discussões no campo da Linguística Aplicada - em razão de as respostas não terem contemplado esse olhar, o que será objeto de análise. 
Na segunda seção de conteúdo, analisaremos as concepções situadas nos domínios teóricoepistemológico e metodológico juntamente, dadas as interpenetrações desses domínios. Para tal análise, abordaremos as questões fechadas, cujos enunciados foram: "Qual(is) a(s) base(s) teórica(s) que ancora $(\mathrm{m}) /$ influencia(m) sua ação como professor(a) de Português?; Como você encaminha a produção textual escrita na sala de aula?; Qual é a periodicidade com que você trabalha a produção textual escrita nas suas aulas na disciplina de Língua Portuguesa?; Os alunos reescrevem o mesmo texto?; Como acontece o processo de reescritura dos textos produzidos por seus alunos?; O que acontece com os textos que seus alunos produzem?". Cada um desses enunciados seguiu-se de uma série de alternativas para resposta objetiva; registraremos, na análise, as alternativas que se mostraram relevantes a partir do objetivo da pesquisa.

Cada uma dessas questões será descrita e analisada, partindo dos questionários em entrecruzamentos com as respostas das entrevistas realizadas, uma vez que os questionários - aplicados a seis informantes - contiveram um espectro mais amplo e exaustivo de itens, mas, por sua própria natureza, não permitem a verticalização da informação, o que foi feito nas entrevistas realizadas com dois dos participantes de pesquisa que haviam respondido ao questionário. O objetivo da entrevista foi essa verticalização, discutindo de modo mais aprofundado as respostas enunciadas no questionário. O retorno dado aos questionários será analisado por frequência de respostas aos diferentes itens; já as entrevistas receberão tratamento qualitativo e remissões via transcrição de falas, facultando-nos maior aprofundamento, o que, em última instância, nos permite discutir criticamente os itens dos questionários e as respostas dadas a eles.

Cinco dentre os docentes participantes da pesquisa são do sexo feminino; um deles é do sexo masculino. Todos têm graduação e especialização. Dos seis, dois graduaram-se na década de noventa, e quatro, após o ano 2000. Com exceção de um professor que ministra aulas há 23 anos e um que ministra aulas há cinco anos, os outros estão na faixa dos quinze anos de magistério. Somente dois professores ministram aulas em uma só escola; o restante ministra aulas em duas e até três escolas. Quanto ao número de turmas, a média varia entre cinco e dezesseis turmas com cerca de trinta alunos em cada uma delas.

\section{O ENSINO E A APRENDIZAGEM DA PRODUÇÃO TEXTUAL: UMA DISCUSSÃO COM BASE NO DOMÍNIO ONTOLÓGICO}

Quando questionados sobre o que é, para eles, produção textual escrita, cada professor definiu a sua maneira, o que concebe como sendo esse processo. Dos seis professores, um não respondeu a essa questão. Obtivemos cinco respostas que categorizamos em: produção textual escrita concebida sob uma perspectiva formalista; e produção textual escrita concebida à luz do ideário do senso comum. 


\subsection{Produção textual escrita concebida sob uma perspectiva formalista}

Entendemos por perspectiva formalista, para as finalidades deste estudo, concepções que se ancoram na compreensão de produção textual como expressão de ideias - veiculação de sentidos -, em uma dimensão psicologista, ou a estruturação do texto tomado como artefato com sentido em sua imanência. Três dos cinco docentes que responderam a esta questão concebem, pelas suas respostas, a produção textual escrita sob o que categorizamos como perspectiva formalista; a resposta transcrita a seguir exemplifica essa compreensão.

(1) É o resultado escrito; o registro de ideias, opiniões, pensamentos etc, construídos de formas diversas e organizados com sentido, havendo planejamento, definição do objetivo, gênero e convenções da escrita quando se trata de um autor já proficiente. (Professora A)

Conceber a produção textual escrita sob essa perspectiva é tomar a língua em sua imanência e abstração ou sob o ponto de vista da faculdade cognitiva que permite a veiculação de mensagens por sujeitos com capacidades individuais de uso da língua, dadas na espécie humana. Bakhtin [Voloschinov] (2006 [1929]) se opõe a duas correntes - que em nossa compreensão estão subjacentes a esse olhar formalista que ancora a produção textual -, que chama de subjetivismo individualista e de objetivismo abstrato, as quais concebem a língua respectivamente sob o ponto de vista do psicologismo idealista ou da imanência sistêmica. $\mathrm{O}$ autor concebe que, para a primeira corrente, toda atividade de linguagem é de criação individual, e que o psiquismo constitui a fonte da língua, ou seja, "[...] as leis da criação linguística são essencialmente as leis da psicologia individual." (p.72). A segunda corrente, ainda segundo o autor, separa a língua da fala e consequentemente separa o universo social do universo individual, concebendo a língua como sistema, construto cristalizado que a coloca fora do fluxo da comunicação verbal. De acordo com o autor, "O sistema lingüístico tal como é construído pelo objetivismo abstrato não é diretamente acessível à consciência do sujeito falante, definido por sua prática viva de comunicação social" (p. 96) e acaba distanciando os falantes da função social da língua. $\mathrm{O}$ autor se opõe a essas correntes, principalmente, porque

\footnotetext{
A palavra dirige-se a um interlocutor: ela é função da pessoa desse interlocutor: variará se se tratar de uma pessoa do mesmo grupo social ou não, se esta for inferior ou superior na hierarquia social, se estiver ligada ao locutor por laços sociais mais ou menos estreitos (pai, mãe, marido, etc.). Não pode haver interlocutor abstrato; não teríamos linguagem comum com tal interlocutor, nem no sentido próprio nem no figurado. (BAKHTIN [VOLOSCHINOV], 2006 [1929], p.112, grifos do autor).
}

A concepção de língua como objeto social se opõe à concepção descrita acima e tem no homem um ser social e historicamente situado, que, de acordo com Vigotski (2008 [1984]), internaliza conhecimentos em apropriações intrassubjetivas a partir de relações intersubjetivas, ou seja, apreende o mundo por meio de interações sociais com outros seres social e historicamente situados. 
A professora cuja resposta ao questionário transcrevemos em (1), quando entrevistada, oscilou entre a visão formalista registrada no questionário e uma concepção de conotação interacional acerca do que seja produção textual escrita. Ora ela informa pedir para que os alunos escrevam textos sem função interacional efetiva, ora informa solicitar a eles que escrevam textos que irão circular socialmente, como textos que serão publicados em folders. Como podemos observar a seguir, quando questionada sobre o que acontece com os textos após serem produzidos pelos alunos, enuncia:

(2) Depende do que combinamos. Tem de tudo. Tem um dia que eles vão fazer só pra professora olhar, que não vai ser avaliado. Tem o dia que eles sabem que a produção vai ser para avaliação. Tem o dia que é feito para ser trocado entre os colegas. Às vezes vai pro mural. Às vezes eles já sabem que o texto é para alguma homenagem na escola, às vezes eles sabem que é um texto que vai ter alguma finalidade para algum evento que está acontecendo na escola. E, às vezes, a produção é para ser feita a leitura, pra ser trocado. Então, depende do que estamos produzindo, do que estamos fazendo. (Professora A)

Dos três professores que responderam à questão aberta concebendo a produção textual escrita sob uma perspectiva formalista, além da professora A, podemos observar o Professor D, que oscila entre uma abordagem formalista e uma abordagem que, ao mencionar a metáfora da viagem, parece ensaiar um enfoque interacional; nos dois professores cujas falas são registradas na sequência podemos observar o predomínio da concepção formalista. Professor D responde que produzir textos escritos na escola: (3) $E$ saber escrever, viajar através da escrita, saber colocar e usar as palavras com sentido e principalmente participar do ato de escrever corretamente. (Professor D) Já o Professor E, embora circule por conceitos da Linguística Textual, se mantém na imanência do texto como artefato. Responde ele: (4) É a habilidade de escrever corretamente com coerência e coesão.

A chamada nova crítica ao ensino de língua, surgida na esfera acadêmica na década de oitenta, postula o texto como unidade básica de ensino da disciplina de Língua Portuguesa. A partir desses novos estudos, o ensino e a aprendizagem da produção textual escrita tem papel fundamental na disciplina, visto que essa deve ter como conteúdos de ensino as práticas de uso da língua, e ao contrário do que podemos perceber nas respostas dadas aos questionários, a produção textual escrita, atualmente, é concebida como processo que tem a interação como objetivo. Para Antunes (2003, p. 45, grifos nossos),

A atividade da escrita,é, então, uma atividade interativa de expressão, (ex-, "para fora") de manifestação verbal das ideias, informações, intenções, crenças ou dos sentimentos que queremos partilhar com alguém, para, de algum modo, interagir com ele. Ter o que dizer é, portanto uma condição prévia para o êxito da atividade de escrever. Não há conhecimento linguístico (lexical ou gramatical) que supra a defíciência do "não ter o que dizer". 
O ensino e a aprendizagem da produção textual escrita parecem, porém, ainda hoje, estar sendo tomados sob uma perspectiva formalista, como podemos depreender na concepção dos professores participantes deste estudo, no que diz respeito ao domínio ontológico. $\mathrm{O}$ nome produção de textos, quando proposto por Geraldi (2006 [1984]), objetivava a instauração de uma nova concepção desse processo e não somente a instituição de uma nova terminologia. O que parece estar acontecendo em muitas de nossas escolas, no entanto, é que o nome mudou de redação para produção de textos, mas as práticas tendem a continuar as mesmas. Para Geraldi (2003 [1991]), os alunos produzem textos para a escola, quando deveriam produzir textos $n a$ escola, pois segundo o autor,

A observação mais despretensiosa do ato de escrever para a escola pode mostrar que, pelos textos produzidos, há muita escrita e pouco texto (ou discurso), precisamente porque se constroem nestas atividades [...] respostas diferentes daquelas que se constroem quando a fala (e o discurso) é para valer. (GERALDI, 2003 [1991], p. 137).

Britto (1997, p. 110, grifos nossos), nessa mesma direção, aponta que "Caberia à escola transformar esses exercícios de redação em práticas efetivas de produção de textos, nas quais os sujeitos apareçam como tais e sua palavra tenha uma razão de ser". Importa que os alunos deixem de produzir textos para a escola; para tanto, as redações, por meio da mediação do professor, devem passar a ser práticas de produção de discursos; se não podem ser efetivamente reais - dado o deslocamento causado devido ao fato de a escola ser uma outra esfera social e não a mesma em que os textos são produzidos -, que tenham como objetivo mostrar aos alunos as diversas formas de utilizar a linguagem escrita o que possa auxiliá-los fora da escola nas situações de interação.

\subsection{Produção textual escrita concebida à luz do ideário do senso comum}

Dentre as cinco respostas, entendemos que duas delas concebem a produção textual escrita à luz do ideário do senso comum, o que nos parece explícito na resposta da Professora B: (5) A produção textual sugere maneiras interessantes e dinâmicas da descoberta do prazer de ler e, consequentemente, do desenvolvimento da leitura e da escrita.

Ao entendermos que essa resposta é concebida à luz do ideário do senso comum estamos sugerindo que esse é um tipo de representação coletiva e social e não individual desta professora. Tomando o conceito de representações da sociologia, Minayo (1995, p.90) escreve que, segundo Émile Durkheim, o

[...] termo se refere a categorias de pensamento através das quais determinada sociedade elabora e expressa sua realidade. Durkheim afirma que essas categorias não são dadas a priori e não são universais na consciência, mas surgem ligadas aos fatos sociais, transformando-se, elas próprias, em fatos sociais passíveis de observação e de interpretação.

Esse é um tipo de concepção que não é construído na universidade e nem na escola. Professores e alunos chegam à escola com representações diversas sobre o ensino, e, 
especificamente aqui, sobre o ensino e aprendizagem de produção textual escrita. Tardif (2002), em pesquisas sobre o ensino nos Estados Unidos, apresenta algumas características dos saberes profissionais dos professores. Segundo o autor, os saberes profissionais dos professores são temporais porque grande parte do que sabem provêm de sua história de vida escolar, ou seja, durante os anos que passaram na escola, os professores estavam imersos no que, atualmente, é seu ambiente de trabalho, e isso faz com que tragam crenças e representações sobre a prática docente; plurais e heterogêneos porque seus saberes provêm de diversas fontes, como cultura social (história de vida e cultura escolar), conhecimentos adquiridos na universidade, de sua experiência profissional e de outros professores, etc.; personalizados e situados, pois suas crenças e representações carregam marcas do contexto em que se inserem.

Atualmente, há várias campanhas/concursos de incentivo à escrita que trazem em seu bojo a relevância desse processo em todos os aspectos da vida social. Essas campanhas trazem como slogan, geralmente, o que consideramos, aqui, como as representações sociais do senso comum do que é produzir textos. Ao responder a questão sobre o que é produção textual escrita à luz do ideário do senso comum, esses professores parecem estar repetindo o que ouvem comumente dentro e fora da escola e relacionando tais conteúdos com, talvez, a única concepção de que se têm apropriado, como podemos ver na resposta da professora C, que diz: (6) É o eixo de todas as instituições. É através da produção textual escrita que se pode avaliar o desempenho do cidadão analisando seus critérios, suas habilidades, seu aperfeiçoamento, ser crítico e argumentativo perante a sociedade. Em entrevista, essa mesma professora oscila entre uma concepção sob uma perspectiva formalista e sob o ideário do senso comum, considera que a produção textual escrita está a serviço dos outros conteúdos disciplinares. Ela enuncia:

(7) Bom, a produção de textos é o seguinte: ela ajuda na gramática, na gramática normativa que nós somos obrigados a aplicar, e não tem como aplicar uma gramática sem conceito, é através do conceito que a gente trabalha com o aluno e, ela sendo explicado o conceito, a produção de textos é muito importante para isso. A coerência no texto, a coesão, se o texto tem nexo. As regras da lingua portuguesa como paragrafação, sinais de pontuação. A produção de textos, ela é tudo. Mesmo porque eu acho que ela é o eixo, é a base da língua portuguesa. Porque a criança sabendo ler, escrever e interpretar, ela está preparada para o mercado de trabalho, lá fora ela vai ser muito bem aceita. E a produção de textos, ela ajuda muito. (Professora C)

Dicotomizamos concepções sob uma perspectiva formalista e sob o ideário do senso comum para fins metodológicos, ainda que reconheçamos eventuais interpenetrações de ambos os enfoques. No discurso da professora C, em entrevista, por exemplo, percebemos que as duas perspectivas se entrelaçam em sua concepção da produção textual escrita. Acreditamos que a perspectiva formalista, tal a herança quase secular que a caracteriza, parece estar sendo/já ter sido incorporada pelo ideário do senso comum, revelando-se muitas vezes no discurso de pais e dos próprios alunos que não concebem a produção textual escrita à luz de uma concepção sociointeracional de linguagem que tome a língua como objeto social. 


\section{O ENSINO E A APRENDIZAGEM DA PRODUÇÃO TEXTUAL: UMA DISCUSSÃO COM BASE NOS DOMÍNIOS TEÓRICO-EPISTEMOLÓGICO E METODOLÓGICO}

Optamos por focalizar, juntamente, os domínios teórico-epistemológico e metodológico dadas as interpenetrações desses domínios. A ancoragem de uma ou outra base teórica é fundamental e tem implicações sobre o tratamento metodológico da produção textual escrita, que, por sua vez, implica na relação dos alunos para/com seus próprios textos. Iniciaremos nosso foco, nesta seção, a partir das questões que nos permitiram depreender em quais bases teóricas os docentes ancoram sua prática pedagógica. Posteriormente, descreveremos as concepções relacionadas ao domínio metodológico, que nos permitiram depreender o encaminhamento dado à produção textual escrita, a periodicidade com que os alunos escrevem, se eles reescrevem seus textos e como o fazem e a finalidade das produções dos alunos.

\subsection{Ancoragem teórica}

Ao serem questionados sobre quais bases teóricas influenciam/ancoram seu trabalho como professores de Português, os participantes deste estudo poderiam assinalar as alternativas: "Teorias sobre classes gramaticais como substantivos, verbos etc.; Teorias sobre funções sintáticas como sujeito, predicado etc.; Teorias sobre concordância, regência, pontuação; Teorias sobre tipologias textuais como narração, dissertação etc.; Teorias sobre gêneros discursivos/textuais como reportagem, crônica etc.; Teorias de letramento; Teorizações sobre sequência didáticas". Cabe ressaltar que os participantes poderiam assinalar mais de uma alternativa e, caso assim o fizessem, deveriam numerá-las em ordem de crescente importância na sua prática pedagógica. Todos os participantes assinalaram mais de uma alternativa, numerando-as. Dos seis, dois assinalaram as teorias sobre tipologias textuais como narração, dissertação etc. com o número ' 1 ', portanto, consideram essas as teorias que mais influenciam/ancoram sua prática.

Atualmente, a nomenclatura tipos textuais vem sendo utilizada em conceituação que não parece ser a que encontramos nas aulas de Língua Portuguesa. Segundo Marcuschi (2002, p.22, grifos do autor), "Usamos a expressão tipo textual para designar uma espécie de construção teórica definida pela natureza linguística de sua composição (aspectos lexicais, sintáticos, tempos verbais, relações lógicas)." O autor cita como sendo tipos textuais: a narração, argumentação, exposição, descrição e injunção. Dessa maneira, os tipos textuais seriam a organização textual interna dos gêneros discursivos/textuais. Mais de um tipo textual podem compor a dimensão textual de um gênero, o que Marcuschi (2002, p. 31) chama de heterogeneidade tipológica.

Ao ancorar suas aulas nas teorias sobre tipologias textuais (que, na escola, englobam, basicamente, os textos narrativos, descritivos e dissertativos), no entanto, os professores não parecem estar usando essa conceituação para tipos textuais, o que acaba por inibir o caráter sociointeracional da produção de texto escrito, pois essas teorias levam em conta somente as características internas do texto. Segundo Silva (1999, p. 89), "Sob esse 
enfoque, a noção de tipo textual assume um caráter de um construto teórico, projetado basicamente para pensar o funcionamento do texto em termos de sua estruturação interna $[\ldots] "$.

Em entrevista, a professora $\mathrm{C}$, ao responder a pergunta sobre quais textos pede para que seus alunos escrevam, enuncia:

(8) Narração. Narrar e descrever é muito bom. Porque a narração é o cotidiano, está na vida deles. Se eles assistem um jogo, é uma narração, o narrador está narrando a partida de futebol. A novela, não deixa de ser uma narração em primeira pessoa, que é o que eu trabalho muito.

Podemos depreender de (8) que a professora concebe tipos textuais como usos da linguagem instituídos, na verdade, pelos gêneros discursivos/textuais, convergência equivocada amplamente discutida contemporaneamente. Segundo Marcuschi (2002, p. 23, grifos nosso) "[...] diferentemente dos tipos de texto, os gêneros de discurso/texto não são construtos teóricos definidos por propriedades linguísticas intrínsecas, mas realizações lingüísticas concretas definidas por propriedades sociocomunicativas".

Cinco dentre os participantes assinalaram as teorias sobre gêneros discursivos/textuais como reportagem, crônica etc. com o número ' 2 ', ou seja, consideram essas teorias como a segunda em que mais ancoram sua prática. De acordo com Bakhtin (1997 [1963]), os gêneros do discurso são tipos relativamente estáveis de enunciado que estão a serviço da comunicação humana. Ainda, segundo o autor, todos os nossos enunciados são construídos/interpretados à luz dos gêneros e os gêneros, ou o domínio deles, são fundamentais para a interação. Schneuwly (2004, p. 28), a partir dos estudos de gêneros de Bakhtin, considera-os como megaistrumentos de interação, e segundo o autor, através dos gêneros é permitido "agir eficazmente numa classe bem definida de situações de comunicação".

Ao ancorar as aulas de produção textual escrita nas teorias de gêneros/discursivos textuais, entendemos haver ressignificações expressivas em se tratando de implicações pedagógicas, pois o ensino passa a ser operacionalizado priorizando a língua em uso, como instituidora das relações sociais em diferentes esferas da atividade humana, e isso faculta aos alunos produzir textos que tenham uma finalidade na sociedade. Teorias e metodologias que priorizam abordagens descoladas do uso, por outro lado, se afastam dessa perspectiva, uma vez que o estudo da língua em sua imanência ou tomado como expressão do psicologismo individual (BAKHTIN/VOLOSCHINOV, 2006 [1929]) prescinde das condições de produção do discurso.

Já em entrevista, as duas participantes deste estudo com as quais nossa interlocução deu-se mais demoradamente, quando questionadas se seguem alguma teoria ou autor específico para ancorar as aulas de produção textual escrita, responderam que não. Como podemos observar em (9), a professora A responde: 
(9) Não. Científico não. A base, mesmo, é a experiência que eu já tenho de 23 anos na sala de aula. E vou buscando. Vou lendo, pegando e trocando ideias e procurando alguma coisa. No caso, agora, fizemos o GESTAR ${ }^{I}$. E no GESTAR tinha bastante ideias, vamos pegando aquilo que já temos, juntando aquilo que já sabemos e vamos procurando sempre trazer coisas novas.

As concepções descritas neste estudo indicam que os participantes têm conhecimento das teorias, sabem de sua importância, mas, em sala de aula, parecem não se ancorar nelas para o trabalho com a produção textual escrita. Em entrevista, a professora A, ao responder quais textos seus alunos produzem com maior frequência, registra:

(11) Na quinta série, eu não costumo repetir a produção. Por exemplo, se já produzimos poema, na próxima produção vai ser carta, ou recado, ou texto narrativo etc. Eles produzem desde um marca páginas, história em quadrinhos, cartazes, fichinha em cima do livro que eu recomendo etc. A sexta série é um pouco disso, mas já começamos um pouco com o texto descritivo, que é uma coisa fácil, para eles. E na sexta série já trabalhamos muito o texto de adivinhação, eles continuam produzindo poemas etc. Mas é, ainda, uma produção um pouco lúdica. Quando chega na sétima e oitava muda um pouco. Na sétima trabalhamos muito a crônica porque depois participamos das Olimpíadas de Lingua Portuguesa e é sempre a crônica, o gênero. Mas eles têm muita dificuldade para produzir crônicas. Eles até entendem, lêem, conversam, eu dou o livro paradidático de crônica, mas na hora de produzir eles confundem muito com o texto narrativo normal. A sétima já produz todos os tipos de texto, às vezes, repete. A oitava, pego muito por causa do ensino médio que são os textos narrativos, descritivos, dissertativos e informativos. Ai a oitava série fecha esses quarto tipos de texto e com muita ênfase no texto dissertativo porque pensamos em preparar para o ensino médio.

Nessa resposta da professora $\mathrm{A}$, inferimos que ela coloca em um mesmo patamar gêneros $e$ tipos textuais, o que sugere ausência de clareza acerca dessas distinções. Parece haver, entretanto, na prática desta professora, um movimento de transição cuja consolidação ainda não se efetivou.

As diretrizes curriculares em nível federal e estadual ${ }^{2}$ postulam os gêneros do discurso/ textuais como objeto de ensino. Segundo Rojo (2008, p.77, grifos nosso), "Os objetivos dos currículos estão voltados às competências e capacidades de leitura e escrita e de fala/escuta, mas os gêneros - em lugar dos tipos de textos (narração, descrição, dissertação, argumentação), tão presentes em décadas anteriores - aparecem como os objetos capazes de desenvolvê-las."

Em nosso entendimento, ao objetificar os gêneros do discurso/textuais, como sugerem os documentos oficiais, corremos um novo risco, pois os conteúdos de ensino deixam de ser as práticas de uso da língua para ser os gêneros, e isso, quando tomado sob uma compreensão

\footnotetext{
${ }^{1}$ GESTAR é um curso de formação continuada de trezentas horas que os docentes participantes da pesquisa, em sua maioria, concluíram no ano anterior.

${ }^{2}$ Parâmetros Curriculares Nacionais (1998) e Proposta Curricular de Santa Catarina (1998).
} 
equivocada, pode levar a objetificar os gêneros em sua imanência, o que, segundo Rojo (2008), pode evidenciar um retorno ao trivium, pois abandonamos as teorias sobre tipologias textuais e colocamos em seu lugar as teorias sobre os gêneros discursivos/textuais, em muitos contextos trabalhadas com os mesmos propósitos formais.

\subsection{Encaminhamento da produção textual escrita}

Ao serem questionados sobre como encaminham a produção textual escrita, os participantes tinham que escolher entre os itens: "costumo aplicar as propostas do livro didático; sugiro um tema e peço que os alunos escrevam sobre ele; sugiro mais de um tema, os alunos escolhem e escrevem sobre; sugiro temas recorrentes no momento, como notícias nos jornais, revistas, etc; sugiro temas presentes no cotidiano dos alunos; costumo mapear os temas de interesse dos alunos e encaminho a produção textual a partir de suas preferências temáticas; uso revistas, jornais e recursos afins para encaminhar a escrita; trabalho com projetos, e as produções escritas são feitas dentro das ações dos projetos; sempre disponibilizo algumas leituras antes para dar referências aos alunos quando escreverem; os alunos escrevem sobre o que quiserem; trabalho com gêneros discursivos/textuais, e a produção textual se dá após o estudo do gênero a ser produzido por meio de leituras diversas".

Também neste item, os participantes poderiam escolher mais de uma opção e numerá-las de acordo com as ocorrências mais frequentes. Em sua maioria, quatro participantes, responderam que trabalham com gêneros discursivos/textuais, e a produção textual se dá após o estudo do gênero a ser produzido por meio de leituras diversas. Dois participantes responderam ser esse o encaminhamento mais frequente, e dois disseram ser esse o segundo encaminhamento mais frequente.

Analisando as entrevistas, entretanto, percebemos que essa não parece ser uma prática recorrente. A professora $\mathrm{C}$, que assinalou o item referido como a segunda prática mais freqüente, não citou em nenhum momento o trabalho com os gêneros. Quando questionada sobre quais textos ela solicita que seus alunos escrevam com maior frequência, ela responde que seus alunos escrevem, em sua maioria, narrações, como podemos ver em (8). Podemos perceber, então, que a professora ancora seu trabalho nas teorias sobre tipologias textuais e não parece haver, em sua prática, o trabalho ancorado nas teorias sobre gêneros discursivos/textuais, o que nos leva a pensar que esse não é o encaminhamento da produção textual escrita.

A nova crítica ao ensino da língua, assim como os documentos oficiais de educação, postulam três eixos para o ensino de língua portuguesa - leitura, produção textual e análise linguística. Os três eixos são inter-relacionados, pois a leitura fornece elementos para a produção textual e esta fornece material para a análise linguística. Embora não concordemos com a análise linguística somente em favor da produção textual, pois entendemos que deva se dar também em favor da leitura, acreditamos que devemos fornecer subsídios, através de leituras diversas, para que os alunos tenham o que dizer, para 
quem dizer e como dizer ao produzirem seus textos. Segundo Geraldi (2003 [1991], p. 137), as condições de produção de textos são:
a) que se tenha o que dizer;
b) se tenha uma razão para dizer o que se tem para dizer;
c) se tenha para quem dizer o que se tem a dizer;
d) o locutor se constitua como tal, enquanto sujeito que diz o que diz para quem diz;
e) se escolham as estratégias para realizar (a), (b), (c) e (d).

Nessa concepção de caráter sociointeracional, não podemos solicitar aos alunos que produzam textos sem antes darmos bases para que consigam realizar tal atividade. Isso não parece ser uma prática recorrente em sala de aula em se tratando do universo deste estudo, pois, dos seis professores-participantes da pesquisa, três disseram sugerir temas recorrentes no momento, como notícias nos jornais, revistas etc. como a primeira alternativa mais frequente.

Ao sugerir temas e solicitar que escrevam, estamos pedindo aos alunos para que produzam redações e não produções de textos. Ao ser questionada se os alunos leem antes de produzirem seus textos, em entrevista, a professora $\mathrm{C}$ responde que sim, pois sabe que as aulas de leitura são importantes devido ao fato de seus alunos não serem leitores e, em seguida, questionada sobre como acontecem as aulas de leitura, enuncia: (12) Nós vamos à biblioteca, pegamos um livro a cada mês pra fazer uma prova. Eles levam pra casa, e depois fizemos um relatório. Esse relatório, às vezes é manuscrito, às vezes é oral. Isso nos faz crer que os alunos não estão lendo para fornecer subsídios à produção textual escrita, mas possivelmente para fazer as tradicionais fichas de leitura.

Para Geraldi (2003 [1991], p. 163), facultar o ter o que dizer ao aluno "não se trata mais, num tal projeto, de devolver à escola o que a escola diz, mas sim de levar para a escola o que a escola também não sabe [...]". Dessa maneira, os alunos podem, por si sós, escreverem textos em que sejam autores e não reprodutores de discursos que não são seus, mas são frutos de suas reflexões como sujeitos situados em um tempo e um espaço.

A professora A, ao ser questionada se seus alunos leem antes de produzirem textos, informa que sim, que as leituras partem de diversos materiais, como o livro didático, paradidático, revistas, jornais etc. E, ao ser questionada sobre quais os objetivos da leituras realizadas, responde: (13) Porque são ideias novas. Eles vão reconstruir o seu pensamento a partir daquilo que leem. Também porque geralmente o texto que vamos produzir tem a estrutura já na leitura. É a base, é o começo, para eles verem já algo produzido. Podemos depreender, a partir da resposta dada pela professora $\mathrm{A}$, que há um objetivo na leitura, diferente do objetivo da professora $\mathrm{C}$; aquela utiliza os textos lidos como exemplos, como modelos, o que foge à teoria dos gêneros/discursivos, pois devemos lembrar que os gêneros são tipos de enunciados relativamente estáveis (BAKHTIN, 1997 [1963]), ou seja, são maleáveis e não modelos pré-fixados, pois como vimos os gêneros são instrumentos que medeiam a comunicação social e, portanto, são constituídos cultural e socialmente de acordo com as necessidades da sociedade. 
Em resposta a outra questão, sobre o que considera ser a produção textual escrita a professora A diz:

(14) A produção de textos é sempre o resultado de algo que eu já fiz durante muito tempo na sala de aula. Vai ser sempre o final de um trabalho, o resultado de alguma coisa que já foi trabalhado. É através de leituras, pesquisas, da internet; tudo aquilo que possa contribuir para chegar ao final termos uma produção. Uma produção escrita que sempre tem um objetivo. Às vezes, essa produção fica limitada à escola, e à sala de aula. Mas é sempre o resultado de alguma coisa. O principio é o texto e a conclusão é a produção de texto.

Podemos depreender que para, esta professora a produção de textos não é algo que deva ser trabalhado avulsamente e que está sempre relacionada a algo que já está sendo trabalhado, o que consideramos um ganho em relação a práticas em que alunos produzem textos sem uma preparação efetiva para tal.

\subsection{Periodicidade da produção textual escrita}

$\mathrm{Na}$ questão sobre a periodicidade da produção textual escrita, os participantes poderiam assinalar uma alternativa entre as seguintes: "uma aula por semana; duas aulas por semana; mais de duas aulas por semana. Quantas?; há produção textual em todas as aulas; a produção textual é quinzenal; a produção textual é mensal; depende do uso do livro didático - sigo o livro e, quando o livro propõe, encaminho o trabalho; não há um período sistemático; trabalho de acordo com as necessidades dos alunos; trabalho com projetos/unidades temáticas ou afins, e a produção textual se dá ao final de cada unidade de trabalho; outra periodicidade. Qual?".

Dentre os seis professores, dois assinalaram que não há um período sistemático, pois trabalham de acordo com as necessidades dos alunos. Está claro que deveria haver mais uma questão perguntando o que os professores entendem por "necessidades dos alunos", pois, dependendo disso, a produção textual escrita pode acontecer em todas as aulas ou uma vez por bimestre. Segundo os PCNs LP (1998, p. 37).

As necessidades dos alunos definem-se a partir dos objetivos colocados para o ensino. As possibilidades de aprendizagem, por sua vez, definemse a partir do grau de complexidade do objeto e das exigências das tarefas propostas. Ambas - necessidades e possibilidades são determinadas pelos conhecimentos já construídos pelos alunos.

Como podemos inferir, a partir dos PCNs LP, não há como basear a atividade de produção textual escrita nas necessidades dos alunos, pois essas serão muitas e seguramente complexas e de difícil sistematização. Devemos, então, definir quais os objetivos pretendidos com tal atividade para, à luz desses objetivos, saber quais as necessidades dos alunos e assim poder focalizá-las. Não há, também, conteúdos designados para determinada série ou idade, mas sim objetivos, que, ao serem trabalhados, mostrarão quais pontos englobam as necessidades dos alunos que servirão de objetivos para práticas futuras. 
A professora $\mathrm{C}$, em entrevista, ao ser solicitada a descrever a sistematicidade das aulas de produção de textos, enuncia:

(18) Não sei, porque já faz parte das minhas aulas. Por exemplo, hoje eu já fiz produção textual. Hoje eu trabalhei uma história, com a sétima série, entre o Carioca, que foi passar o carnaval em Recife e eu não dei o final, eu pedi que eles dessem o final. Já é uma produção textual. Amanhã eles vão ler. E pra sexta-feira eles estão fazendo uma montagem de frases. Nós estamos recortando palavras e eles estão montando frases, que tenha nexo, claro. Através dessas frases, eles irão desenvolver o texto. Então, o texto, ela está sempre presente. Falando agora, assim, que eu percebi. Eu acho que eu nunca desenvolvi uma aula que não tenha produção de texto.

Acreditamos que não deva haver uma sistematicidade rígida, mas a atividade de produção textual escrita não pode ocorrer em períodos que não sejam pré-estabelcidos, como dentro de um projeto ou plano de trabalho elaborado previamente. Deve haver um planejamento das atividades de leitura, produção textual e análise linguística de maneira que essas atividades ocorram imbricadas (GERALDI, 2003 [1991]).

A questão que se coloca ao analisarmos o discurso da professora $\mathrm{C}$ não é somente o fato de não haver uma sistematicidade, mas sim a forte relação com a sua concepção de produção textual escrita e, como mencionado anteriormente, é concebida à luz do ideário do senso comum. $\mathrm{O}$ fato de a produção textual escrita não ter o caráter sociointeracional, as práticas de usos da língua não serem os conteúdos abordados em suas aulas possivelmente justifique por que a atividade não tem um período sistemático e não acontece inserida dentro de um plano de trabalho previamente estabelecido.

A professora $\mathrm{A}$ assinalou que trabalha com projetos/unidades temáticas, e a produção textual se dá ao final de cada unidade de trabalho. Em entrevista, ela explica:

(19) Depende do andamento. Com a sétima série, no ano passado nós produzíamos com muita frequência. Tem turmas que custo a motivá-los a escrever e demora um pouquinho mais. E como a produção de textos, para mim, é sempre o resultado final eu não chego na sala e digo: - Hoje nós vamos fazer um texto. - Do nada. Sempre tem um objetivo. Então, há turmas que chegam nesse objetivo mais rápido, turmas que demoram um pouquinho mais. Mas a frequência, assim, eu acredito que tem turmas que produzimos de quinze em quinze dias, tem turma que levam uns vinte dias.

A partir das falas da professora A, aqui analisadas, inferimos que as atividades de produção textual escrita acontecem inseridas em uma unidade de trabalho, como defendemos, pois, como pontua Antunes (2003, p. 27), importa colocar em xeque "[...] a prática de uma escrita improvisada, sem planejamento e sem revisão, na qual o que conta é, prioritariamente, a tarefa de realizá-la, não importa "o que se diga" e o "como se faz"”. 


\subsection{Reescritura da produção textual}

Todos os seis professores responderam que seus alunos reescrevem o mesmo texto. De acordo com os PCNs LP (1998, p. 77), “[...] a refacção faz parte do processo de escrita. [...] Um texto pronto será quase sempre produto de sucessivas versões. Tais procedimentos devem ser ensinados e podem ser aprendidos" e essa atividade não deve ser encarada como higienização do texto, mas como reestruturação.

Ao responderem que seus alunos reescrevem o mesmo texto, os docentes deveriam responder a outra questão que focalizava como esse processo acontece; eles poderiam assinalar entre as alternativas: "os alunos os reescrevem passando a limpo; os alunos lêem e revisam seus textos para reescrever uma melhor versão que a anterior; eu procuro ajudá-los, leio os textos e indico os problemas e eles reescrevem tentando melhorar; eu os ajudo no quadro, em outra aula, listo os problemas que encontrei nos textos; eu procuro ajudá-los. Leio os textos e tento trabalhar os problemas encontrados por meio de outros materiais e exercícios; Na prática acontece diferente. Como?".

Quatro docentes registraram que os alunos reescrevem passando a limpo, quatro informaram procurar ajudá-los lendo os textos e indicando os problemas, e cinco mencionaram que os ajudam, leem os textos e tentam trabalhar os problemas encontrados por meio de outros materiais e exercícios. Os participantes assinalaram, como podemos observar, mais de uma alternativa, o que nos faz crer que as diferentes práticas acontecem simultaneamente.

A partir das alternativas assinaladas, podemos depreender que a prática desses docentes alternam entre simples correções em que não há um trabalho focalizando os problemas diagnosticados e um trabalho feito com o intuito de promover a "profunda reestruturação do texto", tal qual vimos nos PCNs LP (1998, p. 77).

Ainda segundo os documentos,

Os procedimentos de refacção começam de maneira externa, pela mediação do professor que elabora os instrumentos e organiza as atividades que permitem aos alunos sair do complexo (o texto), ir ao simples (as questões linguísticas e discursivas que estão sendo estudadas) e retornar ao complexo (o texto). Graças à mediação do professor, os alunos aprendem não só um conjunto de instrumentos linguísticodiscursivos, como também técnicas de revisão (rasurar, substituir, desprezar). Por meio dessas práticas mediadas, os alunos se apropriam, progressivamente, das habilidades necessárias à autocorreção. (PCNs LP, 1998, p. 78).

O processo de reescritura não deve ser reescrever somente, mas sim um processo que tenha atividades implicadas que objetivem trabalhar os problemas apresentados pelos alunos. Apesar de cinco professores terem respondido trabalhar os problemas por meio de outros exercícios que tenham como objetivo melhorar a versão seguinte da produção textual 
escrita, novamente, a partir das entrevistas, não podemos depreender que essa seja uma prática recorrente. A professora $\mathrm{C}$, ao ser questionada se os alunos reescrevem o mesmo texto, responde:

(20) É dificil. Se eu faço isso, é uma vez de reescrita. Não tem como em quatro aulinhas. o professor que diz que reescreve todos os textos, eu tenho que ver, eu não acredito. Eu tenho 38 alunos, em média, por turma. São 38 folhinhas, aí eles pegam e reescrevem. Me devolvem. Se eu não gostei, eles reescrevem novamente e me devolvem. Não tem como.

Desse enunciado, mais uma vez, depreendemos que, na prática, não acontece o que foi assinalado, e isso parece decorrer da concepção do que é produção textual escrita para essa professora, como vimos na seção em que analisamos as concepções relacionadas ao ponto de vista ontológico. Em entrevista, a professora A, ao explicar como o processo de reescritura acontece, enuncia:

(22) Por exemplo, na quinta e sexta série, eu tenho o hábito de já reescrever com eles na minha mesa ou na carteira deles. Os que não têm muitas dificuldades, que eu já sei que são alunos que já têm um domínio, que já conseguem fazer bem, fazem por conta deles e depois eu olho e dou uma ideia. Mas aqueles que têm dificuldade eu fico junto, e vou interferindo no texto, vou chamando atenção. Eles vão fazendo e eu vou mostrando. É quase um processo. E mesmo assim, depois eu faço a correção. Da sétima e oitava pra frente já é outra postura. Eu levo pra casa, olho, faço as anotações tudo a lápis, às vezes a caneta. Depende da situação. Eu devolvo pra eles com uma informação, uma crítica, uma avaliação etc. Ainda, às vezes, não valendo nota. Eles têm um tempo para refazer e, nesse tempo, se eles têm duvidas, eles me procuram. Na sétima série, trabalhamos com o gênero entrevista, antes de eles chegarem na comunidade, passou por mim algumas vezes, até cinco vezes. Para que ficassem perguntas adequadas ao nosso objetivo. Não vai direto, sempre passa por mim. E a oitava série, é o mesmo esquema. Eles já conseguem fazer, perguntar por que eu sublinhei ou se não entenderam. Então, já tem esse retorno.

Mais uma vez, podemos depreender que parece não haver análise linguística ou atividade que vise trabalhar os problemas dos alunos como assinalado anteriormente. $\mathrm{O}$ que inferimos ocorrer é um processo de reescritura que se limita ao ato de passar o texto a limpo, como assinalaram quatro docentes no questionário. Isso nos coloca uma questão muito importante que é: Como nossas pesquisas e estudos acadêmicos têm repercutido no meio escolar? De que forma nossas teorizações têm contribuído efetivamente para potencializar a ação docente em se tratando do ensino e da aprendizagem da produção textual escrita? Podemos depreender, pelas respostas dadas pelas docentes em entrevistas, que o processo de reescritura tende a acontecer na busca de solucionar problemas dissociados das implicações discursivas do ato de escrever, tematizando questões que dizem respeito a características internas dos textos, tomados na imanência. 


\subsection{Destino da produção textual escrita}

Para focalizar o destino dado aos textos dos alunos, propusemos uma questão cujo enunciado foi: "O que acontece com os textos que seus alunos produzem?". Para responder a essa questão os professores tinham as seguintes alternativas: costumo corrigir os texto e devolver a eles; os textos são expostos em murais na escola; os textos são lidos em voz alta; costumo produzir livrinhos reunindo os textos; publicamos os textos em meio eletrônico. Qual?; deixo a critério dos alunos o destino que querem dar a seus textos; outra destinação. Especifique. Os professores poderiam escolher mais de uma alternativa e numerá-las, como nas questões analisadas anteriormente. Dos seis professores, quatro informaram costumar produzir livrinhos reunindo os textos. Dois assinalaram ser essa a prática mais frequente, e dois assinalaram ser a terceira prática mais frequente.

De acordo com os PCNs LP (1998), no processo de produção textual escrita devem-se levar em conta as condições de produção dos textos, entre as quais está a finalidade do texto, o que inclui a quem e a quê o texto se destina. Esse é um dos desafios enfrentados por professores de Língua Portuguesa, pois, dar um destino a tantos textos e tentar tornar a situação mais real possível implica ação metodológica complexa.

Apesar de grande parte dos professores terem informado organizar livrinhos com as produções dos alunos, em entrevista percebemos que essa não parece ser uma prática muito recorrente. A professora $\mathrm{C}$ não citou em nenhum momento essa alternativa e, quando questionada sobre o que acontece com os textos após serem produzidos, diz: (15) Eu recolho e olho pra eles. Alguns fizemos uma análise. Eu devolvo, e eles colam no caderninho deles, porque além de conter a nota, quando eles tiram menos de sete eu quero a assinatura dos pais.

Podemos depreender de (15) que os alunos parecem escrever para nota, para o professor olhar e não para interlocutores reais. Em entrevista, a professora A, entretanto, diz que

(16) Depende do que combinamos. Eles sempre sabem antes qual o objetivo. Tem de tudo. Tem um dia que eles vão fazer só pra professora olhar. Tem o dia que eles sabem que a produção vai ser para avaliação. Tem o dia que é feito para ser trocado entre os colegas. Todos os textos, eles lêem. Isso é sagrado. Eu não obrigo a ler, eu pergunto quem quer. Então, é uma prática que temos. Antigamente, eu tinha o hábito de eleger os melhores textos e produzir um livrinho, mas eu percebi que isso não estimula tanto a produção. Eu percebi que estimulava mais uma competição e às vezes não era uma produção deles, era uma produção que tinhas algumas mãozinhas. Por isso saiu do meu objetivo. É ler pra ler na sala, pra todo mundo conhecer. As vezes vai pro mural. As vezes eles sabem que o texto vai ter alguma finalidade, para algum evento que está acontecendo na escola. E, às vezes, a produção é para ser feito a leitura, pra ser trocado. Na oitava série, fizemos os folders, e o objetivo era chamar atenção da escola inteira, então sabíamos que aquilo iria ser entregue íamos nos desfazer daqueles textos. Então, depende do que estamos produzindo, do que estamos fazendo. 
Deste enunciado podemos perceber, mais uma vez, que esta professora parece estar em transição entre práticas que eram comuns no passado e práticas ancoradas nas novas teorias advindas da Linguística Aplicada. Consideramos uma transição, pois ora os textos têm uma finalidade social, ora eles são somente para a professora avaliar. Interessante é que, ao produzirem textos que circularam em folders, exemplo dado pela professora com a turma da oitava série, não é considerado o caráter real e interacional dos textos, a finalidade de serem distribuídos na escola, e sim o fato de que eles iriam se desfazer do texto.

Após a resposta transcrita em (16), perguntamos à professora se ela sente diferença quanto ao estímulo dos alunos dependendo do destino a ser dado ao texto, visto que ela diz combinar com eles antes de eles produzirem. Ela responde que sim:

(17) A quinta e sexta, eles querem publicar tudo, mas não se preocupam com a qualidade. Para eles, está bom de qualquer jeito. A sétima e oitava, às vezes, eles são preocupados com a finalidade do texto. Eles têm medo de não fazer aquilo adequado com a finalidade do texto. Então, eles se policiam mais. Se for para produzir pra mim é uma preocupação, se é pra outro professor é outra preocupação. Como a entrevista que eles fizeram para a sociedade, já é outra preocupação. Outra que eles fizeram que tiveram que ir em lugares públicos, como posto, e eles tinha que ler, era outra. Tem relação com a finalidade, sim. Da qualidade e até mesmo da motivação com que eles fazem a atividade.

A professora admite, em seu enunciado, sentir que seus alunos se interessam mais em produzirem textos que terão algum destino, uma finalidade que não seja a de o professor olhar e guardar ou colar no caderno, mas as práticas não parecem ter sofrido muitas mudanças ainda, visto que, dos seis professores, três assinalaram que corrigir e devolver aos alunos é prática recorrente.

\section{CONSIDERAÇÕES FINAIS}

Considerando que o sujeito se constitui, tal qual Bakhtin [Voloschinov] (2006 [1929]) postula, na alteridade, mediado pela linguagem, e o texto/enunciado é a materialização dos usos da língua nas interações instituídas por meio dos gêneros discursivos/textuais que são instituidores das relações humanas, cabe ao professor de Língua Portuguesa, no processo de estudo da língua em uso propiciar aos seus alunos, aprender a interagir criticamente em sociedade por meio dos gêneros.

A nova crítica ao ensino da língua, desde a década de oitenta, propõe o ensino operacional e reflexivo da linguagem (BRITTO, 1997) em oposição a um ensino em que o texto entra na sala de aula como pretexto para o trabalho de conceitos gramaticais e não como uma demanda da sociedade. As teorias advindas da Linguística Aplicada advogam em favor desse ensino visto que têm como objeto problemas linguísticos socialmente relevantes que exijam respostas teóricas visando a ganhos para as práticas sociais e seus participantes, no sentido de uma melhor qualidade de vida. 
Desse modo, ensinar língua portuguesa ancorando as aulas nas teorias de gêneros discursivos textuais não é simplesmente uma opção, mas sim uma necessidade social, visto que, é preciso considerar que a escola não recebe apenas alunos oriundos de classes privilegiadas, mas também de classes em que as práticas de leitura e produção de textos divergem ou muitas vezes são demasiado restritas. A atividade de produção textual além do trabalho com especificidades como problemas de codificação, formação de sentenças, parágrafos e de textualização, entre outros, permite o acesso a práticas de escrita necessárias à mobilidade social e também ao ensino da variedade linguística socialmente privilegiada.

As questões discutidas, neste artigo, apontam que certo conhecimento da teoria de gêneros discursivos/textuais perpassa as concepções docentes, visto que em questionários responderam, em sua maioria, haver trabalho relacionado a essas teorias. As análises das entrevistas, entretanto, sugerem que, apesar de terem certo conhecimento das teorias, as práticas em sala de aula não convergem, em nenhum dos domínios discutidos, com uma abordagem de natureza sociointeracional, tal qual o estado da arte documenta em se tratando das discussões sobre o tema. Um exemplo foi a entrevista com a professora C, cuja ação didático-metodológica se distingue, em quase todas as questões programadas de concepções ancoradas nas teorias de gêneros discursivos/textuais, e tais teorizações parecem não perpassar nenhuma das implicações de sua prática, o que fez com que, em alguns momentos, a entrevista tivesse um curso diferente do programado. Já a entrevista com a professora A ocorreu com as questões programadas, mas em análise percebemos várias oscilações, o que nos faz crer que parece estar ocorrendo um momento de transição em sua prática pedagógica.

O fato de os professores terem certo conhecimento dessas teorias parece ser, por si só, grande ganho. Considerando, no entanto, que a potencialidade de uma teoria, no campo da Linguística Aplicada, está na apropriação dos que leem e estudam essa teoria a fim de fazer dela ancoragem para sua prática, podemos arriscar supor que esses professores têm tido contato com as teorias, mas tais contatos não têm se convertido em elaborações didáticas que efetivamente ressignifiquem práticas didático-pedagógica no ensino e na aprendizagem da produção textual escrita. Esse entendimento que faz com que infiramos que o novo ideário está ali, mas ainda não houve efetiva apropriação; perpassa as falas, mas não está ainda incorporado às práticas.

Essas reflexões suscitam várias perguntas, mas uma dentre elas não cala: Por que o resultado de nossos empreendimentos acadêmicos nesse campo não consegue incidir sobre isso? Respostas surgem, entre elas as condições políticas com que nossos professores convivem e sob as quais precisam trabalhar. Além de salários baixos, falta de verbas etc., os estudos feitos nas universidades nesse campo não parecem ter o destino a que se prestam - a sala de aula. Dessa maneira, as novas teorias chegam através de cursos de formação continuada que não parecem atingir seus objetivos visto que não conseguem incorporar mudanças, limitando-se a propô-las. Há vinte anos, no mínimo, estão em campo essas "novas" propostas, e elas parecem ainda não ter sido incorporadas nas práticas escolares 
nem por professores com mais tempo na sala de aula e possivelmente, nem por professores mais jovens, como sugere este estudo.

\section{REFERÊNCIAS}

ANTUNES, Irandé. Aula de português - encontro \& interação. São Paulo: Parábola Editorial, 2003.

BAKHTIN, M. Os gêneros do discurso In: Estética da criação verbal. São Paulo: Martins Fontes, 2010 [1963]. p. 261-270

BAKHTIN, M. [VOLOSCHINOV]. Marxismo e filosofia da linguagem: problemas fundamentais do método sociológico na ciência da linguagem. 12. ed. São Paulo: Hucitec, 2006 [1929].

BRASIL. SEF. Parâmetros curriculares nacionais: terceiro e quarto ciclos do ensino fundamental: língua portuguesa. Brasília: MEC/SEF, 1998.

BRITTO, Luiz Percival Leme. A sombra do caos: ensino de língua $x$ tradição gramatical. Campinas, SP: Mercado de Letras, 1997.

GERALDI, João Wanderley (org.). O texto na sala de aula. São Paulo: Ática, 2006 [1984].

. Portos de passagem. 2. ed. São Paulo: Martins Fontes, 2003 [1991].

MARCUSCHI, L. A. Gêneros textuais: definições e funcionalidade. IN: DIONÍSIO, A. MACHADO, A. R.; BEZERRA, M. A. Gêneros textuais e ensino. Rio de janeiro, Lucerna, 2002. p. 19-36

MINAYO, M. C. S. O conceito de representações sociais dentro da sociologia clássica. In: GUARESCHI, P.; JOVCHELOVITCH, S. (Orgs.). Textos em representações sociais. 2.ed. Petrópolis: Vozes, 1995. p. 88-115

ROJO, Roxane. Gêneros de discurso/texto como objeto de ensino de línguas: um retorno ao trivium? In: Signorini, I. (org.). (Re)discutir texto, gênero e discurso. São Paulo:Parábola, 2008. p. 73-108

SANTA CATARINA. SEED. Proposta curricular de Santa Catarina: educação infantil, ensino fundamental e médio: disciplinas curriculares. Florianópolis: COGEN, 1998. 
SCHNEUWLY, B. Gêneros e tipos de discurso: considerações psicológicas e ontogenéticas. In: Gêneros orais e escritos na escola. SCHNEUWLY; B.; DOLZ, J. Campinas: Mercado de Letras, 2004. p. 19-34

SILVA, Jane Quintiliano G. Gênero discursivo e tipo textual. Scripta, Belo Horizonte, v. 2, n. 4, p. 87-106, 1999.

TARDIF, M. ET al. Os professores face ao saber docente: esboço de uma problemática do saber docente. Revista teoria e educação. Porto Alegre, n.4, 1991, 215-233.

VIGOTSKI, L.S. A formação social da mente. 6. Ed. São Paulo: MARTINS Fontes, 2008 [1984]. 